\title{
Acesso e intersetorialidade: o acompanhamento de pessoas em situação de rua com transtorno mental grave
}

| ${ }^{1}$ Igor da Costa Borysow, ${ }^{2}$ Juarez Pereira Furtado I

Resumo: Neste artigo, abordamos o acesso de pessoas em situação de rua com transtorno mental grave aos serviços públicos de saúde mental. Para tanto, realizamos revisão narrativa sobre o tema. Concluímos que os serviços de Assistência Social têm frequente contato com essa parcela da população, oferecendo respostas às suas necessidades, como moradia e resgate de direitos civis. Os serviços de saúde mental ainda apresentam dificuldades em estabelecer estratégias para o atendimento às pessoas em sofrimento mental na própria rua e em inseri-las em CAPS e UBS. Desse modo, a rede socioassistencial tem sido frequentemente a porta de entrada dessa população aos serviços de saúde mental, indicando que o trabalho intersetorial precisa ser mais bem desenvolvido para a efetividade do acesso à rede pública de saúde.

> Palavras-chave: assistência social; saúde mental; intersetorialidade; louco de rua; acesso a serviços.

\author{
${ }^{1}$ Mestre em Ciências da Saúde \\ pela Unifesp. Pesquisador do \\ Laboratório de Avaliação de \\ Programas e Serviços (LaborAl). \\ Endereço eletrônico: igorsow@ \\ yahoo.com.br \\ ${ }^{2}$ Doutor em Saúde Coletiva \\ (Unicamp/UMontreal) e \\ Pós-doutorado em avaliação \\ de programas e serviços de \\ saúde mental (Unicamp). \\ Departamento de Políticas \\ Públicas e Saúde Coletiva, \\ Unifesp, e LaborAl. Endereço \\ eletrônico: juarezpfurtado@ \\ hotmail.com
}




\section{O problema}

A garantia de acolhimento e tratamento às pessoas em sofrimento mental grave na comunidade é objeto da rede de serviços descentralizados e territorializados, como os Centros de Atenção Psicossociais (CAPS), os CAPS para tratamento do uso abusivo de álcool e outras drogas (CAPS AD), os CAPS para atendimento infantil (CAPSi), os Serviços Residenciais Terapêuticos (SRT) e os Centros de Convivência, configurando o novo modelo assistencial em saúde mental no Brasil (BRASIL, 2001). Mais recentemente, as unidades básicas de saúde (UBS) têm sido consideradas porta de entrada preferencial de problemas de saúde mental, incluindo pessoas com transtorno mental grave (TMG) em situação de rua (BRASIL, 2003; BRASIL, 2007).

Alguns desafios têm surgido no acesso aos serviços de saúde mental pela população de rua com TMG. Isso se dá devido a problemas nas equipes e nas políticas públicas, relacionados à dificuldade de organização de ações na rua e à inflexibilidade destas ao se defrontarem com a complexidade comportamental que essa população apresenta ao ser acolhida nos CAPS (ALBUQUERQUE, 2009; SILVA, 2005). Além disso, os SRT são restritos aos egressos de longa internação em hospitais psiquiátricos (FURTADO et al., 2010; FURTADO, 2006), não sendo previstas pessoas em situação de rua.

A política de Assistência Social definiu propostas para a resolução das necessidades ligadas à situação de extrema pobreza, incluindo a garantia de direitos, o acesso a serviços assistenciais, a reconstrução de vínculos sociais e projetos de vida para pessoas em situação de rua e sua inserção em serviços de acolhimento em repúblicas (BRASIL, 2011). Porém, os serviços socioassistenciais têm enfrentado problemas ao lidar com essa população quando apresenta indícios de transtornos mentais, principalmente no que se refere à articulação com os serviços de saúde (ALBUQUERQUE, 2009; SILVA, 2005).

Colocando em destaque o morador de rua em sofrimento mental grave, questionamos seu acesso ao atendimento e acompanhamento nos serviços da rede pública de saúde mental. Para isso, abordaremos o problema na perspectiva dos serviços socioassistenciais, ou seja, buscaremos compreender as questôes ligadas ao acesso e à acessibilidade de moradores de rua aos serviços de saúde mental a partir da intermediação feita pelos serviços e trabalhadores do setor de Assistência Social. 
Realizamos revisão narrativa de literatura a partir do levantamento de produções científicas nacionais a respeito do tema (CORDEIRO et al., 2007; SILVA et al, 2005). Foram utilizadas a base de dados SciELO (Scientific Electronic Library Online) e o banco de teses da CAPES (Coordenação de Aperfeiçoamento de Pessoal de Nível Superior), considerando materiais produzidos a partir de 2001, ano da implementação da lei da Reforma Psiquiátrica Brasileira (BRASIL, 2001). Para a base de dados SciELO, foram buscados os descritores "saúde mental AND moradia OR moradores de rua", sendo encontrados 13 artigos; "saúde mental AND albergue", com 2 novos artigos; e "saúde mental OR assistência social AND intersetorialidade", 2 artigos. No banco de teses da CAPES, foram procuradas as palavras "louco de rua", com resultado de 12 teses, e os termos "moradores de rua" e "saúde mental", que indicaram 5 teses diferentes.

\section{Acesso e acessibilidade}

Com o advento do Sistema Único de Saúde a partir da Lei no 8080, de 1990, a atenção à saúde passou a ser direito de todo o cidadão brasileiro, e o acesso da população aos serviços públicos de saúde foi universalizado pelo Estado (GIOVANELLA; FLEURY, 1996). Além disso, o SUS estabelece como diretriz a equidade, de modo a garantir que o acesso aos serviços contemple as diferenças e desigualdades econômica, social, cultural e de gênero.

No SUS, o acesso está relacionado à noção de acolhimento nas práticas de produção de saúde. A aceitação, o atendimento e aproximação devem nortear o contato entre profissional e usuário, de maneira a permitir a inclusão de cidadãos na rede pública de serviços (BRASIL, 2009a). Dada a importância para a consolidação de um sistema de saúde, o acesso vem sendo objeto de discussões (DONABEDIAN, 1973; ADAY; ANDERSEN, 1974; FRENK, 1985), havendo diferenças teóricas entre os pesquisadores, principalmente em relação aos termos “acesso" e "acessibilidade".

$\mathrm{Na}$ ótica da avaliação da qualidade dos serviços de saúde nos Estados Unidos, Donabedian (1973) divide a acessibilidade em duas dimensões: a) geográfica, referindo-se a aspectos ligados à localização dos serviços, transporte público e distribuição física da rede de saúde; e b) sócio-organizacional, relativa aos aspectos que envolvem a organização interna, como o contato do usuário com a equipe 
e o modo e a diversidade de procedimentos de saúde oferecidos. Ou seja, tão importantes quanto a existência dos recursos seriam as características facilitadoras ou dificultadoras de seu uso pela clientela-alvo (DONABEDIAN, 1973).

Aday e Andersen (1974) empregam o termo "acesso" de maneira ampla, propondo a análise de diferentes variáveis, como a política de saúde, as características do sistema de saúde e da população de risco, a utilização dos serviços e a satisfação da população com eles. Envolve, no conceito de acesso, tanto os aspectos da população como dos serviços de saúde.

Frenk (1985) busca esclarecer as diferenças conceituais entre acesso e acessibilidade a partir da definição de Donabedian, de que esta é o ajustamento entre as demandas da população e os recursos disponíveis pela rede de saúde. Além disso, descreve a acessibilidade como um fator de mediação entre a capacidade dos serviços em produzir cuidado e o consumo desse cuidado. $\mathrm{O}$ conceito de acesso é definido por ele como a capacidade da população em procurar e obter os cuidados em saúde. Contudo, sabendo que a palavra se encontrava no meio de controvérsias teóricas, Frenk decide usar o termo "poder de utilização" para substituí-la. O autor se utiliza de outros conceitos, como disponibilidade (relacionada aos recursos existentes na rede de saúde), uso dos serviços (consumo real do serviço pela população) e resistência (as barreiras que podem surgir no processo de procura e conquista do cuidado).

Em revisão do conceito de acesso, Giovanella e Fleury (1996) propõem as seguintes dimensões: econômica, abrangendo a oferta de atenção à saúde e a demanda da população; técnica, destacando aspectos organizacionais da rede; política, que envolve aspectos de mobilização popular frente à conscientização dos mecanismos sanitários; e simbólica, trazendo as representações sociais sobre a atenção à saúde. Resgatando esse debate, Travassos e Martins (2004) revisaram o tema, inserindo, além das diferenças entre acesso e acessibilidade, um trajeto conceitual sobre a utilização dos serviços.

Parece-nos importante compreender o termo "acesso" de maneira semelhante à preconizada pelo SUS, como entrada e acolhimento dos usuários aos serviços de saúde, definição em que se encaixa a dimensão técnica de acesso (GIOVANELLA; FLEURY, 1996). Usaremos ainda o termo "acessibilidade" para descrever o grau de ajustamento e mediação entre os serviços e as necessidades da população, conforme Donabedian (1973) e Frenk (1985). 


\section{Dimensão do problema}

Nos países da Europa e da América do Norte, a dificuldade de acesso da população de rua a serviços públicos assistenciais tem sido tema de pesquisas no campo das políticas públicas. Em Amsterdam, Holanda, foram entrevistados moradores de rua e observados os serviços de assistência, tanto os sociais como os de saúde (LAERE et al., 2009). Importa salientar que, nesse estudo, a falta de interação entre os serviços de assistência social e saúde foi relatada como um fator de dificuldade no atendimento a essa população. Foram encontradas altas taxas de prevalência de transtornos mentais (67\%) prévios à ida às ruas, que aumentaram ainda mais depois de alguns meses nessa situação.

Um estudo canadense (FITZPATRICK, 2011) investigou programas que indicaram melhores respostas ao tratamento psiquiátrico e ao uso abusivo de álcool e outras drogas através do oferecimento de moradia. Um dos programas, realizado em Nova York, indicou a redução do uso de medicação após 48 meses de ingresso em residências (FITZPATRICK, 2011; GULCUR et al., 2003). Outro indicativo importante foi a eficácia dos atendimentos nas moradias, concluindo que a habitação auxiliou na estabilidade emocional, facilitando também o acesso a tratamentos.

O primeiro levantamento do número de pessoas em situação de rua no Brasil foi realizado na cidade de São Paulo entre 1989 e 1992, e indicou que a maior parcela de moradores de rua era composta por desempregados e pessoas em condição de subemprego (ROSA, 2005). No período de agosto de 2007 a março de 2008, o Ministério do Desenvolvimento Social e Combate à Fome, junto do Instituto Meta, realizou uma pesquisa nacional com objetivo de contagem e caracterização dessa população (META, 2008). A pesquisa foi realizada em municípios de população igual ou superior a 300.000 habitantes, incluindo algumas capitais de estado e o Distrito Federal, totalizando 23 capitais e 48 cidades. Identificaram-se 31.922 pessoas em situação de rua maiores de 18 anos. Acrescentando-se as pesquisas já realizadas em algumas capitais, estimaram-se 50.000 pessoas nessa situação nas cidades com mais de 300.000 habitantes.

Os resultados mostraram que se encontravam em situação de rua $0,061 \%$ da população dessas localidades, em sua maioria homens (82\%), dos quais $69,6 \%$ relataram dormir nas ruas e $22,1 \%$, em albergues ou outras instituiçóes. Uma parcela alternava dormir na rua e em albergues $(8,3 \%)$. Ao serem questionados 
sobre sua preferência, $46 \%$ dos pesquisados informaram que preferiam dormir na rua, por conta da liberdade nos comportamentos e nos horários, e 43,8\% em albergues, apontando o medo da violência e o desconforto como principais motivadores. A falta de liberdade e os horários rígidos foram os motivos mais respondidos como negativos no uso do albergue (META, 2008). A maioria dos entrevistados relatou ter passado por internação em instituições de diversos tipos, e 16,7\% do total informaram já terem sido internados em hospitais psiquiátricos.

Em pesquisa realizada com dez pessoas que viviam nas ruas de São Paulo (ROSA, 2005), comparando-se seu tempo de permanência nos locais de moradia, a casa de familiares apareceu como o local em que essas pessoas moraram pelo maior tempo, seguida dos locais relacionados a trabalho. Na sequência, casas de parentes (que não eram a família nuclear) e instituições de saúde foram indicadas com tempo considerável de estadia; ao final da lista, estavam a rua, as pensões, as famílias constituídas e os albergues. Assim como no levantamento realizado pelo MDS, a vida nas ruas é relatada com maior frequência e duração do que a estadia em albergues, e a frequência em instituições psiquiátricas é relevante.

Em Belo Horizonte, foi realizada pesquisa sobre sintomas de depressão na população em situação de rua (BOTTI et al., 2010). Seus resultados apontaram que $56,3 \%$ das pessoas pesquisadas apresentavam indícios de depressão. Dessa parcela, $24,5 \%$ indicaram grau moderado e $4,9 \%$ apresentavam sintomas graves. Em Juiz de Fora, identificou-se alta taxa de indícios de esquizofrenia entre moradores de rua, 9,6\%, número proporcionalmente superior à população geral brasileira (HECKERT; SILVA, 2002). No Rio de Janeiro, outra pesquisa identificou que $22,6 \%$ da população de um albergue apresentavam distúrbios mentais, e a maioria relatou o convívio com esses problemas antes da ida às ruas (LOVISI et al., 2001). Importante destacar que Botti e seus colaboradores (2010) também reconheceram que muitos dos transtornos mentais encontrados nessa população já estavam presentes antes da ida às ruas, e que a condição de sobrevida que engloba a má alimentação, a falta de qualidade de sono e higiene e a vivência em situaçóes estressoras podem ser desencadeadoras de transtornos mentais.

Em relação aos motivos que levaram essas pessoas a viver nas ruas, o alcoolismo foi citado por 35,5\% dos entrevistados na pesquisa do Ministério da Saúde (META, 2008). A respeito da existência de problemas de saúde na população em situação de rua do sexo masculino, uma pesquisa realizada no Centro de Referência da 
apontou que $28,16 \%$ dos entrevistados afirmaram usar medicação. Desse total, 43,24\% utilizavam psicofármacos, o tipo de medicação mais usado por esse grupo.

\section{Especificidades da clientela}

No Brasil, a população em situação de rua situa-se em uma lacuna entre os serviços públicos, e um grande desafio se coloca quando esses indivíduos apresentam transtornos mentais. O termo "louco de rua" é empregado para identificar essa parcela da população que não está institucionalizada, vivendo em condição de pobreza e sem vínculos com a família (FERRAZ, 2000). Ela carrega o estigma da miséria e da loucura, convivendo com a violência, o medo, o desamparo e a incompreensão da sociedade, ao mesmo tempo em que, por outro lado, valoriza a vida em liberdade (SILVA, 2005).

A imagem do louco de rua atinge diversamente os trabalhadores, resultando em distintas perspectivas. Dentre os diversos posicionamentos, destacam-se: a concepção de "opção pela liberdade", que pode acarretar em desamparo da clientela pelos serviços; a necessidade de institucionalização dessas pessoas e sua consequente retirada das ruas, retomando paradigmas higienistas; o enfoque à refratariedade da clientela a qualquer tipo de abordagem; e o reconhecimento da complexidade dessa clientela, que procura encontrar saídas envolvendo diferentes esferas assistenciais (SILVA, 2005). As diferenças de olhares sobre o público em questão influenciam a atuações dos trabalhadores, o que pode facilitar ou dificultar o acesso aos serviços.

Segundo uma classificação dos modos de viver na rua (MATTOS, 2006) haveria: os mendigos, que vivem do pedido de esmolas e apresentam, na maioria das vezes, uma aparência de descuido que aponta sua situação de miséria e desassistência; os moradores estabelecidos nas ruas das grandes cidades, buscando diversos meios de sobrevivência, e que podem ou não querer amparo nos serviços de assistência; os albergados, que pernoitam nos albergues e passam o dia nas ruas; os catadores de materiais recicláveis, que encontraram uma alternativa específica para conquistar seu sustento; os trecheiros, nômades que transitam entre cidades, procurando trabalhos temporários ou apoios institucionais; os andarilhos, que muitas vezes viajam a pé, sem rumo definido; e o louco de rua, caracterizado por seu transtorno mental, e que na maioria 
dos casos se estabelece em locais onde cria moradias com objetos encontrados. Mattos (2006) nos afirma que essa classificação não é estática, podendo se mesclar conforme as necessidades de cada pessoa.

A Política Nacional da Assistência Social (PNAS) define seu público como aqueles em situação de vulnerabilidade e risco social, com dificuldades de acesso às políticas públicas e inserção no mercado de trabalho formal ou informal (BRASIL, 2004). Castel (2010) define a vulnerabilidade como uma zona instável que se relaciona à precariedade do trabalho e ao enfraquecimento dos apoios e vínculos sociais. É relacionada não apenas a populações miseráveis, mas também a pessoas com limitações de qualquer ordem. Seria uma fase intermediária entre a integração social e a invalidação social ou a desfiliação, quando as relaçôes do indivíduo se tornam insuficientes frente a sua inscrição familiar e social, tornando-o desprotegido. A exclusão social, que geralmente traz em seu conceito a ideia de margem, é entendida pelo autor como um processo que acontece no seio da sociedade, na relação direta entre as pessoas, numa sociabilidade perversa.

De forma parecida, Adorno (1997) descreve o processo de vulnerabilidade, focando a população de rua, em três fases: o acontecimento que provoca a fragilidade psicológica ou social; a dependência dos serviços socioassistenciais; e a quebra dos vínculos sociais, originada pelos sucessivos fracassos na resolução de seus problemas. Essa população passa a viver em "circuitos de marginalidade" e a depender dos serviços institucionais (ADORNO, 2007).

A falta de vínculo familiar e as dificuldades em estabelecer relações e planejamentos para a vida são fatores que poderão desencorajar a procura desses sujeitos pelos serviços públicos. Seus vínculos sociais fragilizados fazem com que essa população crie estratégias de sobrevivência na relação com outros atores sociais, como a invenção de histórias e personagens ao se apresentarem (ADORNO, 2007) e o uso os odores fortes e da falta de higiene como proteção e isolamento (ARISTIDES; LIMA, 2009).

A população em situação de rua, em geral, procura raramente os serviços de saúde, buscando com maior frequência os serviços da assistência social (VARANDA; ADORNO, 2004). Muitas vezes, essas pessoas resistem aos sintomas, e, quando procuram a rede de saúde, estão com vários problemas acumulados e não conseguem mais lidar sozinhas com as dores ou resistir a elas. De outro modo, elas chegam aos serviços de saúde quando são levadas por 
programas específicos ou pelas instituições socioassistenciais. Essas instituições,

por estarem mais próximas da população de rua, acabam sendo a porta de entrada para a rede pública.

A forma como chegam ao serviço de saúde influencia a possibilidade de atendimento: sujos, sem tomar banho e com odores fortes, podem ser mal recebidos na sala de espera, tanto por funcionários como por outros usuários dos serviços, e ter seu acesso impedido (ARISTIDES; LIMA, 2009). Essas experiências muitas vezes vão desencorajar futuras procuras e inserções nos serviços de saúde.

Trata-se de uma clientela com especificidades que fogem às características apresentadas pelos usuários do setor saúde, gerando refratariedades de diversas ordens, as quais terão consequências para o acesso e a acessibilidade aos serviços de saúde mental, como discutiremos a seguir.

\section{Entre a Assistência Social e a Saúde Mental}

Tentativas de acesso de pessoas em situação de rua aos serviços de saúde mental são frequentemente intermediadas pela Assistência Social. Esse setor, historicamente constituído por ações assistencialistas e clientelistas (VARANDA; ADORNO, 2004), tem apresentado avanços com a implementação do Sistema Único de Assistência Social (BRASIL, 2011). A Política Nacional de Assistência Social (2004) dividiu seus serviços em Proteção Social Básica e Proteção Social Especial, esta última voltada para ações que atendam pessoas em risco pessoal e social que já tiveram seus direitos violados. Fazem parte dessa vertente o CREAS-POP (Centro de Referência para a População em Situação de Rua), os serviços de acolhimento, como os albergues noturnos ou unidades institucionais de passagem (BRASIL, 2009), e as equipes de abordagem de rua.

Os trabalhadores da política socioassistencial com frequência são os primeiros a perceber os distúrbios mentais na população em situação de rua, apesar de não poderem concluir diagnósticos (SILVA, 2005), necessitando do apoio das equipes de saúde mental. A vinculação da população de rua ao serviço socioassistencial e à moradia é muitas vezes apontada como condição para o início do tratamento psicossocial, e permite o acesso e a continuidade dos tratamentos nos serviços de saúde (ALBUQUERQUE, 2009; BORYSOW, 2012). Frequentemente, os trabalhadores da assistência social se deparam com a recusa do atendimento por parte dos serviços de saúde, sob a alegação 
de que o morador de rua não tem referências ou um responsável para, por exemplo, controlar a medicação (VARANDA; ADORNO, 2004), ou não porta documentos de identificação (BORYSOW, 2012). Quando é necessária a internação, familiares ou outras referências pessoais são exigidas para que se possa realizar esse procedimento (ARISTIDES; LIMA, 2004).

Essa clivagem entre problemas "sociais" e "de saúde" foi encontrada na pesquisa realizada em um albergue na cidade do Guarujá, São Paulo (BORYSOW, 2012). Foram descritos relatos de servidores que acolheram pessoas no albergue que vivenciaram surtos psicóticos e outros problemas de saúde mental, e que haviam estado antes no hospital geral ou no prontosocorro. A equipe do hospital decidiu que era necessário resolver o "problema social”, antes, para então iniciar algum atendimento ou tratamento de saúde, e encaminharam as pessoas ao albergue. $\mathrm{O}$ acolhimento desses usuários e a articulação da equipe do albergue, junto a uma técnica do CAPS local, possibilitaram uma recepção posterior dessas pessoas no atendimento de saúde.

Os serviços de saúde mental, em geral, não estão preparados para o atendimento extramuros que não seja o domiciliar. Há um relato de um CAPS em Recife (ALBUQUERQUE, 2009) que formou uma equipe para atendimento à população de rua, mas que ainda encontra dificuldade em assumir esses casos. São poucos os servidores que fazem parte dessa ação, e as visitas às pessoas nas ruas são raras. Essa equipe de saúde mental espera que a de assistência social resolva primeiro as questôes da moradia e dos direitos sociais, para depois iniciar o tratamento (ALBUQUERQUE, 2009). Um CAPS em Porto Alegre montou um programa para atuar junto à equipe da assistência social de abordagem de rua; porém, ela só está presente quando solicitada por essa equipe socioassistencial (SILVA, 2005). Em Londrina, Paraná, a rede de assistência social implantou um projeto para atendimento aos moradores de rua (ARISTIDES; LIMA, 2009), mas, quando eles precisam de atendimento médico, é apenas o programa que faz a articulação com o serviço de saúde, conseguindo um atendimento de qualidade. Quando o morador de rua resolve ir por conta própria para a unidade de saúde, muitas vezes não é atendido.

Apesar do acolhimento, observa-se em alguns serviços da assistência social a reprodução de um modelo higienista (VARANDA; ADORNO, 2004), no qual a pessoa em situação de rua passa a ser enquadrada em programas que buscam 
apenas os diagnósticos e intervenções médicas, auxiliando as prefeituras na remoção dessas pessoas das ruas para os equipamentos sociais. Tais iniciativas são frequentemente eivadas do discurso missionário de que a assistência social acolhe os problemas que outros setores não resolveram (ALBUQUERQUE, 2009; VARANDA; ADORNO, 2004), o que desqualifica ou ignora a complexidade e as necessárias ações intersetoriais na efetividade da assistência.

A evidente dificuldade de acesso dos moradores de rua com TMG parece ser oriunda das limitações dos serviços de saúde mental em se adaptar às necessidades específicas dessa clientela. A ausência de vínculos interpessoais de grande parte da população de rua com TMG desafia os programas, organizados de forma a buscar apoio da rede familiar ou de convivência. A frequente falta de estratégias para a busca ativa e para o acolhimento dessa população nos serviços de saúde mental impede a ampliação do acesso. Outras exigências também são obstáculos, como a falta de endereço de referência e a falta de documentos de identificação, problemas assumidos pela Assistência Social. Isso ilustra fortemente um impasse: a dificuldade de acesso de usuários que apresentam necessidades nos âmbitos social e mental aos CAPS.

\section{Discussão: a acessibilidade como mecanismo da intersetorialidade}

A intersetorialidade entre Saúde e Assistência Social é embasada no pertencimento de ambas à chamada Seguridade Social (MONNERATI; SOUZA, 2011). Ela propõe um diálogo entre as políticas públicas da Previdência Social, Saúde e Assistência Social; porém, cada área se desenvolve de maneira isolada. Ao investirem em seu próprio fortalecimento, esses setores acabam competindo entre si, na tentativa de divulgar melhores resultados ao governo e à sociedade. Além disso, a preocupação com as fontes financiadoras desses setores impede a construção de um orçamento unificado.

Nesse sentido, percebe-se o Ministério da Saúde em um movimento isolado, preocupado em não perder sua identidade fortalecida pelo SUS. A Previdência Social centraliza suas decisões e sua burocracia se encapsula sem precisar se preocupar com os demais setores, já que conta com recursos garantidos (MONNERATI; SOUZA, 2011). A Assistência Social tem avançado na implementação de seus serviços, aumentando consideravelmente o número de CREAS pelo país, mas 
os CREAS-POP ainda não alcançaram todos os estados brasileiros (FEITOZA, 2012). Outro desafio desse setor se refere à permanência de algumas práticas das equipes, que tendem a trazer para si atribuições que fortaleçam a setorialidade, a institucionalização e a dependência da população aos serviços (SILVA, 2005).

A implementação da intersetorialidade também é dificultada pela resistência dos representantes setoriais em modificar suas agendas quando estão em negociação. As discussões realizadas entre grandes escalōes e gestores do governo costumam ter relativo sucesso, mas percebe-se dificuldade na implementação das ações intersetoriais, no plano dos municípios e respectivos serviços, onde as propostas encontram conflitos políticos e outras influências locais (MAGALHÂES; BOLDSTEIN, 2009).

A intersetorialidade desafia as organizações a planejar e executar suas ações de uma maneira nova, observando a rede de relações possíveis a cada contato com os usuários, cujas demandas e necessidades não são pautadas pela noção de setorialidade ou intersetorialidade (JUNQUEIRA, 2004).

Tomando como base a realidade das unidades, os trabalhadores dos serviços socioassistenciais, em geral, reconhecem a necessidade de atuarem em contato com vários programas da Secretaria de Saúde, em destaque os serviços de saúde mental, e apontam a prevalência de moradores de rua com TMG como justificativa (VARANDA; ADORNO, 2004). A Assistência Social frequentemente é porta de entrada para os serviços públicos e para a rede de saúde mental em particular, quando se trata dessa população.

A presença das equipes de saúde mental nos albergues não foi identificada nas pesquisas sobre o assunto (ALBUQUERQUE, 2009; SILVA, 2005; MATTOS, 2006; VARANDA; ADORNO, 2004; ARISTIDES; LIMA, 2009; BRITO, 2003), exceto no Guarujá (BORYSOW, 2012), onde foi relatada a presença semanal de uma técnica do CAPS. Essa ação permite maior acessibilidade dos frequentadores do albergue aos cuidados em saúde mental, representando um avanço nas práticas intersetoriais.

Outra experiência a ser destacada é o trabalho com população de rua em sofrimento mental realizado por uma UBS em Belo Horizonte (BRITO, 2003). Localizada na região central da cidade, ela montou uma equipe de saúde mental que mantém contato com os serviços socioassistenciais e a rede de saúde mental. Sendo a UBS a porta de entrada preferencial do SUS para os serviços de saúde, 
tendo uma equipe especializada e estando perto de uma região de vulnerabilidade, a acessibilidade da população de rua com TMG aos serviços públicos é então mais bem ajustada.

A intersetorialidade constitui modos de organizar serviços e setores para aproximá-los das reais necessidades dos potenciais usuários, cujas demandas e necessidades naturalmente não são percebidas por eles próprios de maneira compartimentada (JUNQUEIRA, 2004). Dessa forma, a acessibilidade dos serviços não é somente a concretização da atenção requerida, mas também um fator necessário na efetivação do trabalho entre setores.

\section{Conclusão}

O acesso aos serviços de saúde mental da população de rua em sofrimento mental apresenta grandes obstáculos, oriundos das condições de privação de direitos e vulnerabilidade apresentadas por essa clientela, mesmo com a intermediação frequente dos serviços de assistência social nesse processo (ALBUQUERQUE, 2009; ARISTIDES; LIMA, 2009; BORYSOW, 2012; SILVA, 2005; VARANDA; ADORNO, 2004). A dificuldade da população em acessar diretamente os serviços de saúde faz com que os serviços da assistência social hipertrofiem seu papel junto à clientela, além de privar a população de rua do atendimento e da reabilitação psicossocial de que necessitam.

Os obstáculos à acessibilidade dessa população aos serviços de saúde ocorrem também pelas dificuldades das equipes em planejar estratégias que exijam adaptações no funcionamento cotidiano dos serviços e das equipes de saúde (ALBUQUERQUE, 2009; ARISTIDES; LIMA, 2009; BORYSOW, 2012; SILVA, 2005, VARANDA; ADORNO, 2004). Nos serviços de saúde mental, foram apontados problemas de organização e iniciativa das equipes frente ao trabalho de busca ativa a esses potenciais usuários, bem como dificuldades em acolhê-los de maneira adequada nos CAPS (ALBUQUERQUE, 2009; SILVA, 2005). A falta de moradia e de referências dificulta o traçado de estratégias para o tratamento medicamentoso, e ainda se fala pouco a respeito de iniciativas das UBS em acolher essa população. As exigências dos serviços de saúde para possibilitar o acesso parecem fortalecer o funcionamento setorializado, e muitas vezes fica a cargo das equipes da assistência social iniciar a articulação com toda a rede de saúde, atuando também como referências para os usuários. 
Frente às dificuldades já apontadas na articulação intersetorial, podemos concluir que a efetivação de ações intersetoriais precisa vencer os obstáculos políticos nas três esferas de governo e avançar na formulação de modelos tecnoassistenciais condizentes com a realidade aqui discutida. Consideramos que as noções de acesso e acessibilidade são referenciais importantes para a análise da assistência prestada à clientela enfocada, no contexto nacional de desinstucionalização, e também para o avanço no estabelecimento de colaborações verdadeiramente intersetoriais ${ }^{1}$.

\section{Referências}

ADAY, L.A.; ANDERSEN, R. A framework for the study of access to medical care. Health Serv Res., v.9, p.208-20, 1974.

ADORNO, R.C.F. Os imponderáveis circuitos dos vulneráveis cidadãos: trajetórias de crianças e jovens das classes populares. In: SÃO PAULO. Secretaria da Justiça e da Defesa da Cidadania. Cidadania, verso e reverso. São Paulo: Imprensa Oficial, 1997/1998. p. 93-109.

ALBUQUERQUE, C.M. C. Loucos nas ruas: um estudo sobre o atendimento à população de rua adulta em sofrimento psíquico na cidade do Recife. 2009, 136p. Dissertação (mestrado) - Universidade Federal de Pernambuco, Pernambuco, 2009.

ANDRADE, W.V.; BOTTI, N.C.L. A saúde mental na atenção básica - articulação entre os princípios do SUS e da reforma psiquiátrica. Cogitare Enferm., v.13, n.3, p.387-94, jul-set, 2008. ARISTIDES, J.L.; LIMA, J.V.C. Processo saúde-doença da população em situação de rua da cidade de Londrina: aspectos do viver e do adoecer. Rev Espaço para a Saúde v.10, n.2, p.43-52, jun 2009.

ASSIS, M.M.A.; VILLA, T.C.S.; NASCIMENTO, M.A.A. Acesso aos serviços de saúde: uma possibilidade a ser construída na prática. Ciênc. saúde coletiva, v.8, n.3, p.815-823, 2003. BORYSOW, I.C. Assistência Social e Saúde: acesso de pessoas em situação de rua aos serviços de saúde mental. In: CONGRESSO BRASILEIRO DE SAÚDE MENTAL, 31, 2012, Fortaleza. Anais... Fortaleza: ABRASME, 2012, no prelo.

BOTTI, N.C.L. et al. Prevalência de depressão entre homens adultos em situação de rua em Belo Horizonte. J Bras Psiquiatr., v.59, n.1, p.10-16, 2010.

BRASIL. Ministério do Desenvolvimento Social e Combate à Fome. Conselho Nacional da Assistência Social. Resolução no 109, de 11 de novembro de 2009. Tipificaçãa Nacional de Serviços Socioassistenciais. Brasília: MDS, 2009b.

BRASIL. Lei no 10.216, de 6 de abril de 2001. Dispóe sobre a proteção e os direitos das pessoas portadoras de transtornos mentais e redireciona o modelo assistencial em saúde mental. Diário Oficial [da] República Federativa do Brasil, Brasília, DF, 2001, 6 abr. 
BRASIL. Lei no 12.435, de 6 de julho de 2011. Altera a Lei no 8.742, de 7 de dezembro de 1993, que dispõe sobre a organização da Assistência Social. Diário Oficial [da] República Federativa do Brasil, Brasília, DF, 6 jul. 2011.

BRASIL. Ministério da Saúde. Política Nacional de Atenção Básica. Série Pactos pela Saúde. Brasília, v.4, 2007.

BRASIL. Ministério da Saúde. Saúde Mental e Atenção Básica: O vínculo e o diálogo necessários. Boletim do no01/03 da Coordenação de Saúde Mental e Coordenação de Gestão da Atenção Básica, Brasília, 2003. Disponível em: <http://portal.saude.gov.br/portal/arquivos/ pdf/diretrizes.pdf>. Acesso em: 12 fev. 2012.

BRASIL. Ministério do Desenvolvimento Social e Combate à Fome. Secretaria Nacional de Assistência Social. Politica Nacional de Assistência Social. Brasília: MDS, 2004.

BRASIL. Sus de A a Z. $3^{a}$ edição, Completo, Brasília, 2009a. Disponível em: <portal.saude. gov.br/portal/arquivos/pdf/sus_3edicao_completo.pdf >. Acesso em: 5 jul. 2012.

BRITO, M.M.M. Loucos pela rua: escolha ou contingência? 2003. Dissertação (Mestrado em Ciências Sociais) - Pontifícia Universidade Católica de Minas Gerais, Belo Horizonte, 2003.

CASTEL, R. As metamorfoses da questão social: uma crônica do salário. Petrópolis: Vozes, 2010.

CORDEIRO, A.M. et al. Revisão sistemática: uma revisão narrativa. Rev. Col. Bras. Cir., v.34, n. 6, dez. 2007. Disponível em: <http://www.scielo.br/scielo.php?script=sci_ arttext\&pid=S0100-69912007000600012\&lng=en\&nrm=iso >. Acesso em: 13 dez 2011.

DONABEDIAN, A. Aspects of medical care administration. Boston: Harvard University Press, 1973.

FEITOZA, V. Censo SUAS 2011 mostra expansão dos serviços em todo o país. Brasília: Ministério do Desenvolvimento Social e Combate à Fome, 2012. Disponível em: <http:// www.mds.gov.br/saladeimprensa/noticias/2012/julho/censo-suas-2011-mostra-expansaodos-servicos-em-todo-o-pais/?searchterm=censo\%20suas >. Acesso em: 06 jul. 2012.

FERRAZ, F.C. O louco de rua visto através da literatura. Psicol. USP, São Paulo, v. 11, n. 2, 2000. Disponível em: <http://www.scielo.br/scielo.php?script=sci_arttext\&pid=S010365642000000200009\&lng=en \&nrm=iso>. Acesso em: 21 ago. 2012.

FITZPATRICK, D. et al. Effectiveness of interventions to improve the health and housing status of homeless people: a rapid systematic review. BMC Public Health, v.11, p.638, 2011. FRENK, J. Concept and measurement of accessibility. Salud Publica Mex., v.27, p.438-53, 1985. FURTADO, J.P. Avaliação da situação atual dos Serviços Residenciais Terapêuticos no SUS. Cienc. Saude Colet., v.11, n.3, p.785-95, 2006.

FURTADO, J.P. et al. Inserção social e habitação: um caminho para a avaliação da situação de moradia de portadores de transtorno mental grave no Brasil. Interface. Botucatu, v.14, n.33, p.389-400, jun 2010. Disponível em: <http://www.scielo.br/scielo.php?script=sci_ arttext\&pid=S1414-32832010000200012\&lng=en.> Acesso em: 07 abr. 2012. 
GIOVANELLA, L.; FLEURY, S. Universalidade da Atenção à Saúde: acesso como categoria de análise. In: Eibenschutz C., organizadora. Política de Saúde: o público e o privado. Rio de Janeiro: Fiocruz, p.177-198, 1996.

GULCUR, L. et al. Housing, hospitalization, and cost outcomes for homeless individuals with psychiatric disabilities participating in continuum of care and housing first programmes. J Community Appl Soc Psychol., v.13, p.171-186, 2003.

HECKERT, U.; SILVA, J.M.F. Psicoses esquizofrênicas entre a população de rua. Rev Psiq Clin., v.29, n.1, p.14-9, 2002.

JUNQUEIRA, L.A.P. A gestão intersetorial das políticas sociais e o terceiro setor. Saúde e Sociedade, v.13, n.1, p.25-36, jan-abr 2004.

LAERE, I.R.; WIT, M.A.; KLAZINGA, N.S. Pathways into homelessness: recently homeless adults problems and service use before and after becoming homeless in Amsterdam. BMC Public Health, v.9, n.3, 2009.

LOVISI, G.M.; LIMA, L.A.; MORGADO, A.F. População de rua e os transtornos mentais maiores: revisão dos aspectos relevantes. J Bras Psiquiatr., v.50, n.6, p.149-60, 2001.

MAGALHÃES, R.; BODSTEIN, R. Avaliação de iniciativas e programas intersetoriais em saúde: desafios e aprendizados. Cienc. Saude Colet., v.14, n.3, p.861-868, 2009.

MATTOS, R.M. Situação de rua e modernidade: a saída das ruas como processo de criação de novas formas de vida na atualidade. 2006, 244p. Dissertação (Mestrado) - Universidade São Marcos, São Paulo, 2006.

META. Instituto de Pesquisa de Opinião. Relatório final. Pesquisa Censitária e Amostral. População em situação de rua. Porto Alegre: Meta, 2008.

MONNERATI, G.L.; SOUZA, R.G. Da Seguridade Social à intersetorialidade: reflexões sobre a integração das políticas sociais no Brasil. Rev. Katálysis, v.14, n.1, p.4149, jan-jun, 2011.

ROSA, C.M.M. Vidas de rua. São Paulo: Hucitec, 2005.

SILVA, E.L.; MENEZES, E.M. Metodologia da pesquisa e elaboração de dissertação. 4a ed. rev. atual. Florianópolis: UFSC, 2005.

SILVA, M.B. O “louco de rua" e a Seguridade Social em Porto Alegre: Da (in) visibilidade social à cidadania? 2005, 141p. Dissertação (Mestrado em Serviço Social) - Pontifícia Universidade Católica do Rio Grande do Sul, Porto Alegre, 2005.

TRAVASSOS C.M.; MARTINS M. Uma revisão sobre os conceitos de acesso e utilização de serviços de saúde. Cad Saúde Publica., v.20, supl.2, p.S190-S198, 2004. 
VARANDA, W.; ADORNO, R.C.F. Descartáveis urbanos: discutindo a complexidade da população de rua e o desafio para políticas de saúde. Saude soc., v.13, n.1, p.56-69, jan-abr, 2004. YIN, R.K. Estudo de caso: Planejamento e métodos. $3^{\text {a }}$ ed. Porto Alegre: Bookman, 2005.

\section{Nota}

${ }^{1}$ I.C. Borysow e J.P. Furtado participaram igualmente da coleta e análise de dados, da discussão dos resultados e da redação final do artigo. 


\section{Abstract}

\section{Access and intersectoriality: tracking street dwellers with severe mental disorder}

In this paper, we address the access of homeless people with severe mental disorder to public mental health care. To this end, we conducted a narrative review on the topic and concluded that Social Welfare services have frequent contact with that portion of the population, providing answers to their needs, such as housing and civil rights of redemption. Mental health services still have difficulty establishing strategies to care for people in mental distress in the street and enter them in CAPS and health units. Thus, the welfare network has often been the gateway of this population to mental health services, indicating that the intersectoral work needs to be further developed to ensure effective access to public health services.

> Key words: social welfare; mental health; intersectoriality; homeless with mental disorder; access to health care. 